\title{
Suitability of common single circuit boards for sensing and actuating in smart textiles
}

\author{
Guido Ehrmann ${ }^{1}$, Andrea Ehrmann ${ }^{2, *}$ \\ 1 Virtual Institute of Applied Research on Advanced Materials (VIARAM) \\ ${ }^{2}$ Bielefeld University of Applied Sciences, Faculty of Engineering and Mathematics, Bielefeld, Germany \\ ${ }^{*}$ Corresponding author E-mail address: andrea.ehrmann@fh-bielefeld.de
}

\section{INFO}

CDAPT, ISSN 2701-939X

Peer reviewed article

2020, Vol. 1, No. 2, pp. 170-179

DOI 10.25367/cdatp.2020.1.p170-179

Received: 04 December 2020

Accepted: 22 December 2020

Available online: 22 December 2020

\begin{abstract}
Single-board computers and microcontrollers such as Raspberry Pi or Arduino are nowadays used in a broad range of applications. Their relatively low power consumption and low price, compact dimensions and relative ease to program them make them suitable for diverse areas of measuring and controlling various parameters. In the textile area, however, such single-board computers are still less often used than in other projects, in spite of their aforementioned advantages in comparison to other solutions. Here we give an overview of the differences between single-board computers and single-board microcontrollers in general, compare different versions and give examples which projects are reported in the scientific literature, in design or in the maker scene, enabling researchers, designers and makers to decide which future projects necessitate which single circuit boards.
\end{abstract}

Keywords

Microcontroller,

Single-board computer,

Single circuit board

Arduino,

RaspberryPi,

Smart textiles,

Smart clothes

(c) 2020 The authors. Published by CDAPT.

This is an open access article under the CC BY-NC-ND license https://creativecommons.org/licenses/ peer-review under responsibility of the scientific committee of the CDAPT.

\section{Introduction}

Smart textiles can be defined in different ways. The "smartness" can be based on inherent material properties, e.g. in case of thermochromics or photochromic materials, changing their color due to temperature or photo-irradiation [1,2]. Smart functions can also be implemented by integration of optical fibers [3], phase change materials [4], or the like. Most smart textiles, however, nowadays include electronics for a broad range of applications, from medical garments sensing body functions [5] to new design opportunities [6].

Typically, smart textiles contain the following components, implemented by textile or textile-integrated parts: sensors and actuators, internal and external communication, a power source and a data processor 
[7]. Many research groups investigate and develop textile sensors and actuators [8-10], think about textile batteries or solar cells [11-13], textile circuits [14,15] and textile-based antennae [16,17], resulting in an increasing number of publications from year to year (Fig. 1).

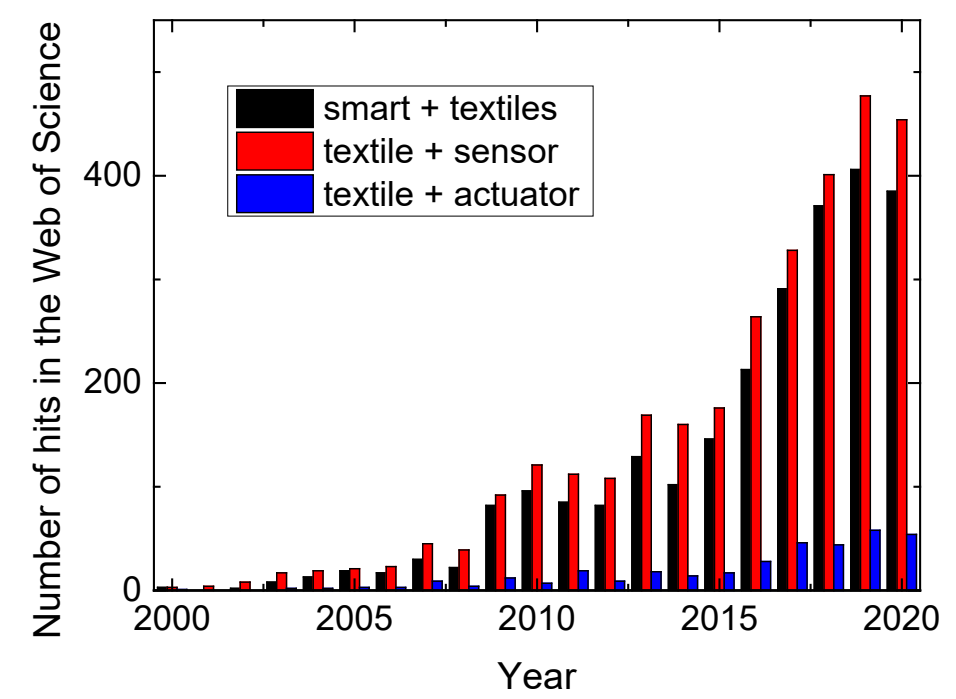

Fig. 1 Numbers of hits for different search phrases in the Web of Science (data accessed on December 5, 2020).

While the integration of diverse electronic elements into textile fabrics, e.g. in the form of automated connection of LEDs with textiles circuits by specialized embroidery machines [18], has already entered the commercial sector, not much research is visible yet in the area of data processing. Obviously, it is not possible to prepare textile-based computers simply due to miniaturization issues. While single textile transistors are investigated for diverse purposes [19-21], reducing their sizes to dimensions which would enable very basic computation on reasonable overall dimensions cannot be imagined at the recent state of technology. Thus, for many smart textile applications, it is necessary to include specialized or more general microcontrollers or single-board computers into the textile fabrics or garments.

Here we give an overview of recent single circuit boards, i.e. single-board computers (SBCs) and singleboard microcontrollers (SBMs), with their advantages and disadvantages, and show recent projects implemented with such single circuit boards, to enable researchers, designers and makers to choose the ideal boards for future projects.

\section{Recent SBCs and SBMs}

Here we concentrate on the most often used SBCs and SBMs, the Raspberry Pi and the Arduino family, which are not necessarily aiming at integration into textile fabrics, and investigate their suitability for combinations with smart textile projects. It should be mentioned that there are several more specialized microcomputers and micro-computers available which may be better suitable for special textile projects; however, the here described SBCs and SBMs are quite often used by makers as well as for lab automation and thus well-known by different groups of people, making them especially suitable in interdisciplinary projects in which, e.g., textile designers or medical engineers work together with electronic specialists.

For a first impression, Fig. 2 shows some of these SBCs and SBMs. Here, the dimensional differences between different boards are already visible, even without showing the LilyPad board or other special textile-related boards. It should be mentioned that there are not only large dimensional differences between SBCs and SBMs, but also inside each family. 

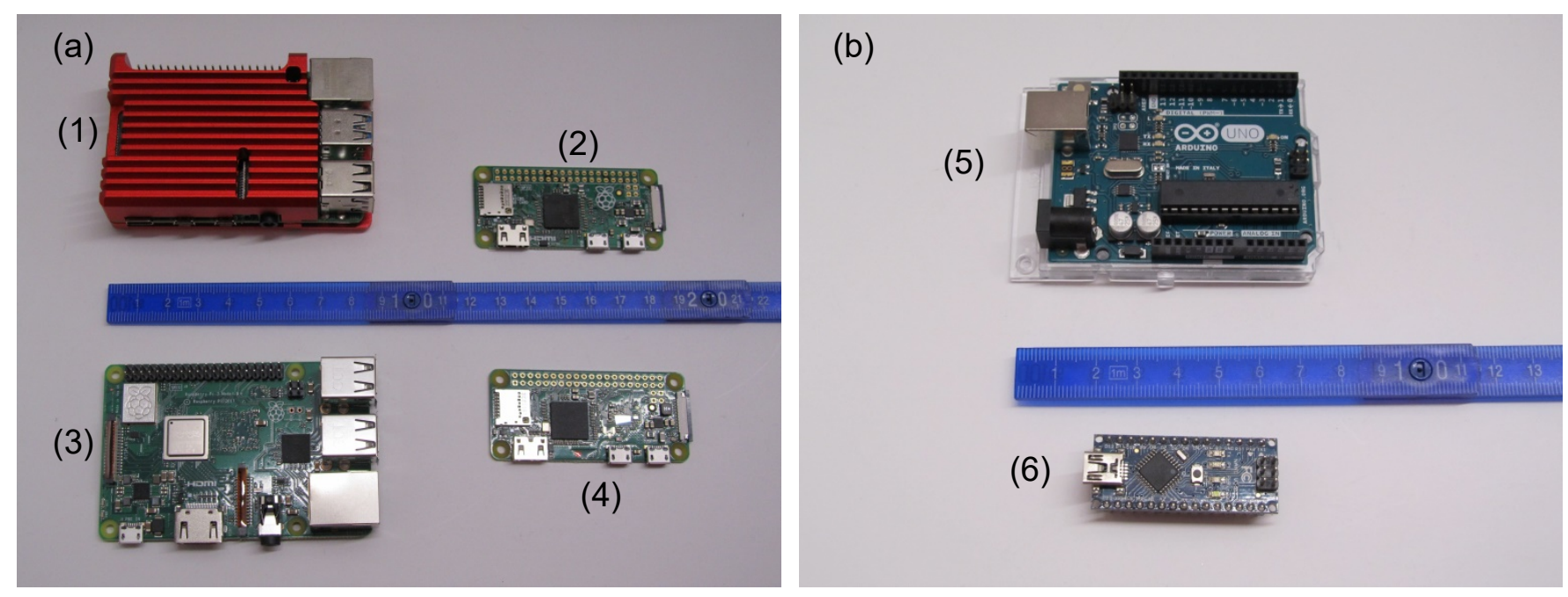

Fig. 2 (a) Different Raspberry Pi (1: Raspberry Pi 4B with passive cooler (red); 2: Raspberry Pi Zero; 3: Raspberry Pi 3B+; 4: Raspberry Pi Zero W) and (b) Arduino boards (5: Arduino UNO; 6: Arduino Nano).

Table 1 gives an overview of typical features of some chosen Raspberry Pi versions; Table 2 correspondingly shows parameters of some chosen Arduinos. It must be mentioned that both tables contain different parameters since some of them are only suitable for SBCs or SBMs - the latter, e.g., do not have cores since they are no full computers but microcontrollers.

Table 1. Technological parameters of some Raspberry Pi computers. From [22].

\begin{tabular}{|c|c|c|c|c|}
\hline Board & Raspberry Pi 4B & Raspberry Pi 3B+ & Rasp. Pi Zero W & Rasp. Pi Zero \\
\hline Price [23] & $€ 38-78$ & $€ 37$ & $€ 11.00$ & $€ 5.50$ \\
\hline SOC & BCM2711 & BCM2837B0 & BCM2835 & BCM2835 \\
\hline Cores & 4 & 4 & 1 & 1 \\
\hline Core Type & Cortex-A72 & Cortex-A53 & ARM1176JZF-S & ARM1176JZF-S \\
\hline CPU Clock & $1.5 \mathrm{GHz}$ & $1.4 \mathrm{GHz}$ & $1 \mathrm{GHz}$ & $1 \mathrm{GHz}$ \\
\hline RAM & 1-8 GB LPDDR4 & 1 GB DDR2 & $512 \mathrm{MB}$ & $512 \mathrm{MB}$ \\
\hline USB 3.0 & 2 & none & none & none \\
\hline USB 2.0 & 2 & 4 & none & none \\
\hline micro OTG & none & none & 1 & 1 \\
\hline Video & 2x micro HDMI & HDMI & mini HDMI & mini HDMI \\
\hline Analog Audio & 3.5 mm jack & $3.5 \mathrm{~mm}$ jack & none & none \\
\hline SPI & yes & yes & yes & yes \\
\hline $\mathrm{I}^{2} \mathrm{C}$ & yes & yes & yes & yes \\
\hline GPIO & 40 pins & 40 pins & 40 pins & 40 pins \\
\hline Storage & microSD & microSD & microSD & microSD \\
\hline WiFi & $802.11 \mathrm{~b} / \mathrm{g} / \mathrm{n} / \mathrm{ac}$ & $802.11 \mathrm{~b} / \mathrm{g} / \mathrm{n} / \mathrm{ac}$ & $802.11 n$ & none \\
\hline Bluetooth & 5.0 & 4.2, BLE & 4.1 & none \\
\hline Size & $85.6 \times 56.5 \times 11 \mathrm{~mm}^{3}$ & $85.6 \times 56.5 \times 17 \mathrm{~mm}^{3}$ & $65 \times 30 \times 5 \mathrm{~mm}^{3}$ & $65 \times 30 \times 5 \mathrm{~mm}^{3}$ \\
\hline Weight & $46 \mathrm{~g}$ & $45 \mathrm{~g}$ & $9 \mathrm{~g}$ & $9 \mathrm{~g}$ \\
\hline Power & 1.25 A@ @ V & 1.13 A @ 5 V & 180 mA @ 5 V & 160 mA @ 5 V \\
\hline Power Connector & USB-C & microUSB or GPIO & microUSB or GPIO & microUSB or GPIO \\
\hline
\end{tabular}


Generally, Raspberry Pi models are full computers, usually with 1-4 cores, up to 8 GB RAM, typically working with a Linux operating system, e.g. Raspberry Pi OS. As Table 1 shows, many features of "common" computers are included, such as video and often also analog audio output, WiFi, USB ports etc. This broad functionality, however, results in relatively large systems, usually with the largest dimension being $65 \mathrm{~mm}$ or $85.6 \mathrm{~mm}$, respectively.

This shows already that these fully functional microcomputers may be more suitable for "larger" projects in a doubled sense - they can perform more complicated tasks, but necessitate also more space than the Arduinos, some of which are exemplarily described in Table 2. Other Arduino IDE-based microcontrollers are available, e.g., from LilyPad (round boards with sewable connections), espressif (the well-known microcontroller ESP8266 with integrated WiFi), etc.

Table 2. Technological parameters of some Arduino microcontrollers. From [24,25].

\begin{tabular}{|c|c|c|c|c|c|}
\hline Board & Arduino Uno & Arduino Nano & Arduino Micro & Ard. Nano 33 BLE & Digispark Mini \\
\hline Price (official) & $€ 20,00$ & $€ 20,00$ & $€ 18,00$ & $€ 17,50$ & $€ 5,00$ \\
\hline Controller & ATmega328P & ATmega328 & ATmega32U4 & nRF52840 & ATtiny85 \\
\hline $\begin{array}{l}\text { Operating } \\
\text { Voltage }\end{array}$ & $5 \mathrm{~V}$ & $5 \mathrm{~V}$ & $5 \mathrm{~V}$ & $3.3 \mathrm{~V}$ & $5 \mathrm{~V}$ \\
\hline Input Voltage & $6-20 \mathrm{~V}$ & $6-20 \mathrm{~V}$ & $6-9 V$ & $4.5-21 \mathrm{~V}$ & $7-35 V$ \\
\hline $\begin{array}{l}\text { Input Voltage } \\
\text { (recommended) }\end{array}$ & $7-12 \mathrm{~V}$ & $7-12 V$ & $7-9 V$ & & \\
\hline $\begin{array}{c}\text { Power } \\
\text { Consumption }\end{array}$ & & $19 \mathrm{~mA}$ & $20 \mathrm{~mA}$ & $<20 \mathrm{~mA}$ & \\
\hline I/O Pins Digital & 14 & 22 & 20 & 14 & 6 \\
\hline $\begin{array}{l}\text { I/O Pins Digital } \\
\text { PWM shared }\end{array}$ & 6 & 6 & 7 & 14 & 3 \\
\hline $\begin{array}{l}\text { I/O Pins Digital } \\
\text { PWM }\end{array}$ & none & none & none & none & none \\
\hline I/O Pins Analog & 6 & 8 & 12 & 8 & 4 \\
\hline UART & yes & yes & yes & yes & no \\
\hline SPI & yes & yes & yes & yes & yes \\
\hline$I^{2} C$ & yes & yes & yes & yes & yes \\
\hline $\begin{array}{l}\text { Current per I/O } \\
\text { Pin (DC) }\end{array}$ & $20 \mathrm{~mA}$ & $40 \mathrm{~mA}$ & $20 \mathrm{~mA}$ & $15 \mathrm{~mA}$ & \\
\hline $\begin{array}{l}\text { Current per 3.3V } \\
\text { Pin (DC) }\end{array}$ & $50 \mathrm{~mA}$ & & $50 \mathrm{~mA}$ & & \\
\hline Flash Memory & $32 \mathrm{~KB}$ & $32 \mathrm{~KB}$ & $32 \mathrm{~KB}$ & $1 \mathrm{MB}$ & $8 \mathrm{~KB}$ \\
\hline SRAM & $2 \mathrm{~KB}$ & $2 \mathrm{~KB}$ & $2.5 \mathrm{~KB}$ & $256 \mathrm{~KB}$ & $0.5 \mathrm{~KB}$ \\
\hline EEPROM & $1 \mathrm{~KB}$ & $1 \mathrm{~KB}$ & $1 \mathrm{~KB}$ & none & $0,5 \mathrm{~KB}$ \\
\hline Clock Speed & $16 \mathrm{MHz}$ & $16 \mathrm{MHz}$ & $16 \mathrm{MHz}$ & $64 \mathrm{MHz}$ & $20 \mathrm{MHz}$ \\
\hline Length & $68.6 \mathrm{~mm}$ & $45 \mathrm{~mm}$ & $48 \mathrm{~mm}$ & $45 \mathrm{~mm}$ & $26 \mathrm{~mm}$ \\
\hline Width & $53.4 \mathrm{~mm}$ & $18 \mathrm{~mm}$ & $18 \mathrm{~mm}$ & $18 \mathrm{~mm}$ & $12 \mathrm{~mm}$ \\
\hline Weight & $25 \mathrm{~g}$ & $7 \mathrm{~g}$ & $13 \mathrm{~g}$ & $5 \mathrm{~g}$ & $2 \mathrm{~g}$ \\
\hline Connector & USB 2.0 Type B & Mini-B USB & Micro USB & Micro USB & USB $2.0 \mathrm{~A}$ \\
\hline Battery & no & no & no & no & no \\
\hline $\begin{array}{l}\text { Programming via } \\
\text { Special Features }\end{array}$ & Arduino IDE & Arduino IDE & Arduino IDE & $\begin{array}{c}\text { Arduino IDE } \\
\text { BLE, Bluetooth }\end{array}$ & Arduino IDE \\
\hline
\end{tabular}


These microcontrollers can only execute compiled C-code and are no stand-alone computers. They are available in smaller dimensions, down to lateral dimensions of $26 \mathrm{~mm} \times 12 \mathrm{~mm}$ for the examples shown here and with a minimum mass of only $2 \mathrm{~g}$. However, the ATmega328P has already similar dimensions and even a higher mass than the smaller Raspberry Pi versions.

Another important factor, comparing both families of single circuit boards, is the power consumption. In both tables, only the power consumption of the board alone is given; each sensor or actor necessitates additional power. While the smallest Raspberry Pi needs a power of $160 \mathrm{~mA} @ 5 \mathrm{~V}$, Arduino microcontrollers typically use $20 \mathrm{~mA} @ 3.3-5 \mathrm{~V}$, allowing for using such a system for much longer times than a Raspberry Pi with the same battery or power-pack.

It must be mentioned, however, that in many cases the additional sensors and actuators need much more power than the boards themselves, often levelling out this difference to a certain amount. Driving, e.g., 20 LEDs with a typical power consumption of $20 \mathrm{~mA} @ 2 \mathrm{~V}$ with one of these systems consumes the same power as a pure Raspberry Pi Zero with the aforementioned $160 \mathrm{~mA} @ 5 \mathrm{~V}$. As visible from Table 2, such relatively high powers cannot be taken from one of the $1 / O$ pins (with a maximum of 15$40 \mathrm{~mA}$ ), but the $\mathrm{I} / \mathrm{O}$ pin can control a relay-based circuit enabling switching higher currents and/or voltages.

Comparing the different Arduino SBMs, several differences become visible, not only related to dimensions and mass, but also to the amount of digital and analog $1 / O$ pins, the flash memory and SRAM, and the clock speed, clearly showing that for each project, the right Arduino or Raspberry Pi has to be chosen.

For a first decision whether an SBC or an SBM is best suited for a planned project, there are different rules of thumb and more sophisticated comparisons available:

- Arduino boards are easier to use for people with low programming experience [26].

- The IDE (integrated development environment) of the Arduino family is platform independent (i.e. usable in Windows, Linux and macOS) [26].

- Several libraries can be included into the IDE of Arduinos, supporting single sensors / actuators or complete sensor / actuator families.

- For many more sophisticated applications, Arduinos need so-called shields which let dimensions, mass and costs increase [26].

- Most Raspberry Pi models contain Ethernet, WiFi or both, while amongst the common Arduinos, only a few, like the Nano 33 BLE, contains Bluetooth LE (BLE).

- Generally, an Arduino can be used for simple, repeated tasks, while a Raspberry Pi is better suited for more sophisticated applications [26]. Both systems can be combined to profit from their respective advantages [27].

- And as a rule of thumb: Projects which can be explained by maximum one "and" can be performed by an Arduino; projects whose descriptions need more than two "and" should be performed on a Raspberry $\mathrm{Pi}[28]$.

Especially for applications in smart textiles, where important features are low power consumption, usability for basic electronics and simple circuits, microcontrollers from the Arduino family are often better suited than Raspberry Pi computers [29]. The next section will introduce several sample projects, making these differences clearer.

\section{Sample projects}

In spite of the large amount of research on smart textiles (Fig. 1), scientific literature on using SBCs or SBMs in such research is scarce. Most recently, Lin et al. gave an overview of the learning outcomes of students in maker-based assessments. They found that amongst the large number of maker platforms, the aforementioned LilyPad Arduino combined with electronic textiles was most popular for measuring 
STEM-related learning outcomes [30]. Serrano-Pérez describes a project with early-year students which should be motivated for learning physics by programming an Arduino Uno for controlling LEDs in garments [31].

An Arduino Uno was also used by Anbalagan et al. for data transmission by a textile antenna in a wearable system [32]. The Arduino, however, was not integrated into the textile material since the development of the textile antenna was the main purpose of this study. Similarly, Oldfrey et al. did not investigate the integration of the not exactly specified Arduino used in their study into a textile environment, but used it only for calibration purposes [33], as visible in Fig. 3. Nuramdhani et al. also used an Arduino Uno as a not-integrated part to investigate a textile energy storage device [34], while Li et al. applied an Arduino ATmega2560 for data collection and visualization of a step pressure sensing and position mapping system, based on textile pressure sensor mats [35]. Frequency-based measurements in smart textiles were also applied by an Arduino Uno placed next to the textile fabric under investigation [36].

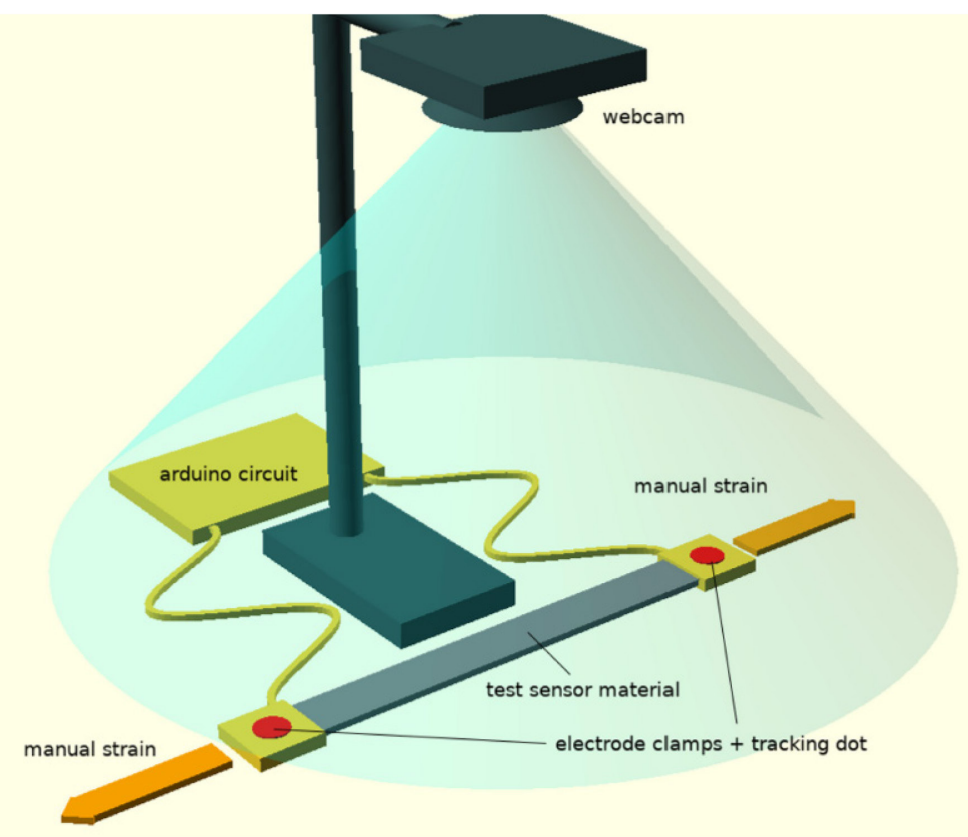

Fig. 3 Experimental setup applying an Arduino-based circuit for resistance measurements during stretching textile strain sensors. From [33], originally published under a CC-BY license.

Raad et al., on the other hand, integrated a LilyPad Arduino into a smart glove which was used to monitor hand joint movements of patients suffering from rheumatoid arthritis, enabling observing the effort of medication or recommended movements [37]. A LilyPad Arduino was also integrated into a sensor sock measuring plantar pressure and acceleration signals, allowing for taking data necessary for postural and gait analysis [38]. An Arduino Nano, positioned at the forearm by an arm band, was coupled with a smart glove used to collect data of the movement of volleyball players during the service [39].

It must be mentioned that even a sophisticated task like measuring an ECG signal was tested by an Arduino-based device. Here, however, Ankhili et al. found that in comparison with a portable medical device, the low-cost Arduino-based solution showed higher distortions of cardiac waveforms and higher noise in case of high-resistant electrodes, suggesting that amplifiers with high input impedance are necessary to compensate the high contact impedance of typical textile electrodes [40].

Such complicated applications are the only ones which were found in the scientific literature as examples for using a Raspberry Pi. Bystricky et al. applied a module Medlab EG05000, connected to a Raspberry $\mathrm{Pi}$, for ECG measurements. The measured data were stored and sent to a mobile device. Using this specific module, they measured reliable ECG signals with embroidered electrodes [41]. 
Similarly, Pina et al. combined a Raspberry Pi B+ with a custom-made circuit for measuring EMG data of different muscles with a sampling rate of $1 \mathrm{kHz}$ and a resolution of 24 bit. With this electronic equipment, gel-based and textile electrodes showed highly similar EMG signals. However, the authors mention that Python as programming language used on the Raspberry $\mathrm{Pi} \mathrm{B}+$ with $700 \mathrm{MHz}$ ARM11 CPU may not be suitable for real-life applications due to the observed CPU workload [42].

In these cases, however, the Raspberry $\mathrm{Pi}$ was not reported to be integrated into the textile fabrics or garments. This is mostly done with the Arduino Nano or an Arduino LilyPad which is especially designed for integration in textile fabrics [43-45], while neither ESP8266 nor Digispark Mini were found in combination with textile fabrics in the scientific literature. Even the Wattuino Nanite85, based on an ATtiny 85 microcontroller and with $\sim 10 \mathrm{~mm} \times 17.5 \mathrm{~mm}$ area much smaller than the LilyPad [46], is not reported for scientific applications in textile fabrics.

In the field of smart textiles, however, scientists are not the only ones investigating new solutions for well-known problems or also testing and extending the technological limits of new functionalities. Already in 2015, a complete issue of the magazine "Make" dealt with Wearables, suggesting several designrelated projects including electroluminescent wires and foils, controlled by diverse specialized microcontrollers, mostly round and sewable for improved integration into textile fabrics [47]. Diameters of the boards shown there are between $14 \mathrm{~mm}$ and $50 \mathrm{~mm}$, i.e. often larger than Arduino Nano or Digispark Mini. The mostly round shape, however, enables wearing these boards unhidden on the outer side of smart clothes, using them as additional design elements, as shown in Fig. $4[48,49]$.
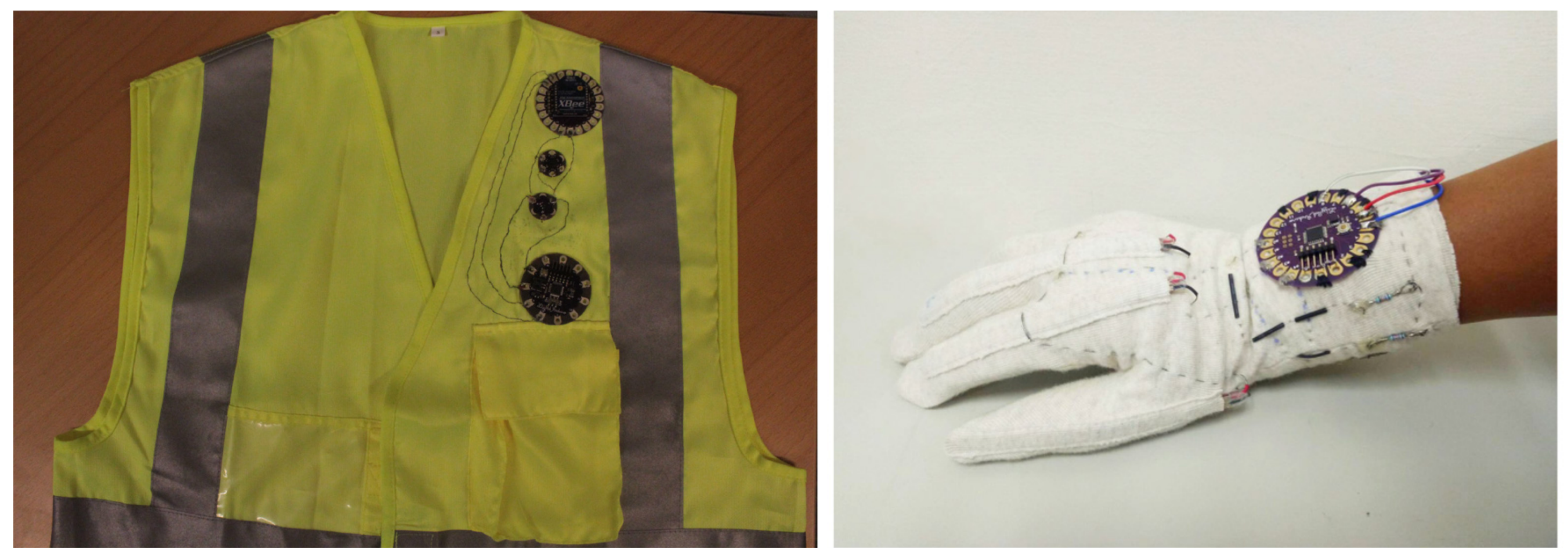

Fig. 4 (a) Safety vest for children, applying an Arduino LilyPad, from [48], originally published under a CC-BY-NCND license; (b) wireless smart glove, from [49], originally published under a CC-BY license.

In the designer and maker scenes, a broad range of highly creative projects exist, mostly based on SBMs. Such projects can be found, e.g., directly on the Arduino website [50] and the sites of more specialized textile-related boards [51,52], but also on maker sites like Instructables [53] or Kobakant [54].

While many of these projects are design- or fun-related and thus their products are often not fully reliable, they can nevertheless offer new and unusual solutions for scientific problems, e.g. related to monitoring vital sensors and other health and safety related issues. Thus they can not only be used by beginners to start coding and start working with typical "smart" materials, especially combining textiles with electronics, but also support researchers by adding creative ideas and new perspectives to old problems.

Besides, especially in research related to tight fitting smart clothes, researchers should go beyond the typical textile-specific boards like LilyPad and the boards used in other areas, such as Arduino Nano, and test the even smaller boards, such as Digispark Mini or Wattuino Nanite85, which may be sufficient 
for several projects, have smaller dimensions and sometimes also lower power consumption than the more often applied SBMs. Finally, the possibility should be taken into account to develop a project on a common Arduino microcontroller, where it can easily be modified, and shift the final software to a pure microcontroller with only the necessary in- and outputs connected, in this way reducing the dimensions as far as possible for a certain project.

\section{Conclusions}

This brief overview of typical single-board computers (e.g. Raspberry Pi) and single-board microcontrollers (e.g. Arduino) shows large differences not only between SBCs and SBMs, but also within the respective families, the latter especially in terms of dimensions, masses and functionalities. The literature survey shows only scarce utilization of SBCs in smart textile projects, while for smart textiles including SBMs, often boards specialized for such textile applications were used. It is striking that many more projects dealing with SBMs are found in the design area and maker scene than in the scientific literature. Besides, it must be mentioned that some of the smallest and thus often well-suited SBMs are nearly never used, indicating a gap between the available electronic solutions and the knowledge about them which should be closed to enable a more inconspicuous integration of electronics in smart textiles.

\section{References}

[1] Staffová, M.; Kucera, F.; Tochácek, J.; Dzik, P.; Ondreás, F.; Jancár, J. Insight into color change of reversible thermochromic systems and their incorporation into textile coating. J. Appl. Polymer Sci., 2021, 138 (4), 49724. DOI: 10.1002/app.49724.

[2] Periyasami, A. P.; Vikova, M.; Vik, M. A review of photochromism in textiles and its measurement. Textile Progress, 2017, 49 (2), 53-136. DOI: 10.1080/00405167.2017.1305833.

[3] Issatayeva, A.; Beisenova, A.; Tosi, D.; Molardi, C. Fiber-optic based smart textiles for real-time monitoring of breathing rate. Sensors, 2020, 20 (12), 3408. DOI: 10.3390/s20123408.

[4] Tang, S. L. P.; Stylios, G. K. An overview of smart technologies for clothing design and engineering. Int. J. Clothing Sci. Technol., 2006, 18 (2), 108-128. DOI: 10.1108/09556220610645766.

[5] Trummer, S.; Ehrmann, A.; Büsgen, A. Development of underwear with integrated 12 channel ECG for men and women. AUTEX Res. J., 2017, 17 (4), 344-349. DOI: 10.1515/aut-2017-0008.

[6] Fafenrot, S.; Silbermann, P.; Grimmelsmann, N.; Assig, J.; Ehrmann, A. Integration of solar cells and other electronic components into clothes. Kyosev, Y.; Mahltig, B.; Schwarz-Pfeiffer, A. (eds.) Narrow and Smart Textiles, 2017, 229-239. Springer, Cham. DOI: 10.1007/978-3-319-69050-6_20.

[7] Schwarz, A.; van Langenhove, L.; Guermonprez, P.; Deguillemont, D. A roadmap on smart textiles. Textile Progress, 2010, 42 (2), 99-180. DOI: 10.1080/00405160903465220.

[8] Catrysse, M.; Puers, R.; Hertleer, C.; van Langenhove, L.; van Egmond, H.; Matthys, D. Towards the integration of textile sensors in a wireless monitoring suit. Sens. Act. A Phys., 2004, 114 (2-3), 302-311. DOI: 10.1016/j.sna.2003.10.071.

[9] Langereis, G. R.; Bouwstra, S.; Chen, W. Sensors, actuators and computing systems for smart textiles for protection. In: Chapman, R. A. (Ed.) Smart textiles for protection, 2013, 190-213. Woodhead Publishing Series in Textiles. DOI: 10.1533/9780857097620.1.190.

[10] Kaynak, A.; Zolfagharian, A. Functional polymers in sensors and actuators: fabrication and analysis. Polymers, 2020, 12(7), 1569. DOI: 10.3390/polym12071569.

[11] Jost, K.; Dion, G.; Gogotsi, Y. Textile energy storage in perspective. J. Mater. Chem. A, 2014, 2, 1077610787. DOI: 10.1039/C4TA00203B.

[12] Heo, J. S.; Eom, J.; Kim, Y.-H.; Park, S. K. Recent progress of textile-based wearable electronics: a comprehensive review of materials, devices, and applications. Small, 2018, 14 (3), 1703034. DOI: 10.1002/smll.201703034.

[13] Ehrmann, A.; Blachowicz, T. Recent coating materials for textile-based solar cells. AlMS Mater. Sci., 2019, 6 (2), 234-251. DOI: 10.3934/matersci.2019.2.234.

[14] Bonderover, E.; Wagner, S. A woven inverter circuit for e-textile applications. IEEE Electron Device Letters, 2004, 25 (5), 295-297. DOI: 10.1109/LED.2004.826537.

[15] Ojuroye, O.; Torah, R.; Beeby, S. Modified PDMS packaging of sensory e-textile circuit microsystems for improved robustness with washing. Microsystems Technologies, 2019.

[16] Kiourti, A.; Lee, C.; Volakis, J. L. Fabrication of textile antennas and circuits with $0.1 \mathrm{~mm}$ precision. IEEE Antennas and Wireless Propagation Letters, 2015, 15, 151-153. DOI: 10.1109/LAWP.2015.2435257 
[17] Del-Rio-Ruiz, R.; Lopez-arde, J.-M.; Legarda, J. Planar textile off-body communication antennas: a survey. Electronics, 2019, 8 (6), 714. DOI: 10.3390/electronics8060714.

[18] Schwarz-Pfeiffer, A.; Obermann, M.; Weber, M. O.; Ehrmann, A. Smarten up garments through knitting. IOP Conf. Series Mater Sci. Eng., 2016, 141, 012008. DOI: 10.1088/1757-899X/141/1/012008.

[19] Coppedè, N.; Giannetto, M.; Villani, M.; Lucchini, V.; Battista, E.; Careri, M.; Zappettini, A. Ion selective textile organic electrochemical transistor for wearable sweat monitoring. Organic Electronics, 2020, 78, 105579. DOI: 10.1016/j.orgel.2019.105579.

[20] Kim, S. J.; Kim, H. J.; Ahn, J. T.; Hwang, D. K.; Ju, H. S.; Park, M.-C.; Yang, H. C.; Kim, S. H.; Jang, H. W.; Lim, J. A. A new architecture for fibrous organic transistors based on a double-stranded assembly of electrode microfibers for electronic textile applications. Adv. Mater., 2019, 31 (23), 1900564.

[21] Owyeung, R. E.; Terse-Thakoor, Tr.; Nejad, H. R.; Panzer, M. J.; Sonkusale, S. R. Highly flexible transistor threads for all-thread based integrated circuits and multiplexed diagnostics. ACS Appl. Mater. Interfaces, 2019, 11 (34), 31096-31104. DOI: 10.1021/acsami.9b09522.

[22] RaspberryPI models comparison. Available online: https://socialcompare.com/en/comparison/raspberrypimodels-comparison (accessed on December 5, 2020).

[23] BerryBase, The Maker Shop. By Sertronics GmbH, Berlin, Germany. Available online: https://www.berrybase.de/ (accessed on December 5, 2020).

[24] Arduino Products. Available online: https://www.arduino.cc/en/Main/Products (accessed on December 5, 2020).

[25] Joy-it Digispark Mikrocontroller. Available online: https://joy-it.net/de/products/ARD-Digispark (accessed on December 5, 2020).

[26] Arduino vs. Raspberry Pi: Mikrocontroller und Einplatinencomputer im Vergleich. Available online: https://www.ionos.de/digitalguide/server/knowhow/arduino-vs-raspberry-pi/ (accessed on December 5, 2020).

[27] Strobel, C. Arduino vs. Raspberry Pi: Wo liegt der Unterschied? Techtag 12/08/2016. Available online: https://www.techtag.de/it-und-hightech/arduino-vs-raspberry-pi-wo-liegt-der-unterschied/ (accessed on December 5, 2020).

[28] Di Justo, P. Raspberry Pi or Arduino Uno? One Simple Rule to Choose the Right Board. Make, Dec. 4, 2015. Available online: https://makezine.com/2015/12/04/admittedly-simplistic-guide-raspberry-pi-vs-arduino/ (accessed on December 5, 2020).

[29] Pounder, L. Raspberry Pi vs Arduino: Which board is best? Tom's Hardware, July 10, 2020. Available online: https://www.tomshardware.com/features/raspberry-pi-vs-arduino (accessed December 5, 2020).

[30] Lin, Q.; Yin, Y.; Tang, X. D.; Hadad, R.; Zhai, X. M. Assessing learning in technology-rich maker activities: A systematic review of empirical research. Computers \& Education, 2020, 157, 103944. DOI: 10.1016/j.compedu.2020.103944.

[31] Serrano-Perez, E. Arduino-based low-cost electronic textiles to introduce electric circuits and programming. Revista Cubana de Fisica, 2019, 36 (2), 110-113.

[32] Anbalgan, A.; Sundarsingh, E. F.; Ramalingam, V. S. Design and experimental evaluation of a novel on-body textile antenna for unicast applications. Microwave and Optical Technology Letters, 2020, 62 (2), 789-799. DOI: $10.1002 / \mathrm{mop} .32075$.

[33] Oldfrey, B.; Jackson, R.; Smitham, P.; Miodownik, M. A deep learning approach to non-linearity in wearable stretch sensors. Frontiers in Robotics and Al, 2019, 6, 27. DOI: 10.3389/frobt.2019.00027.

[34] Nuramdhani, I.; Jose M.; Samyn, P.; Adriaensens, P.; Malengier, B.; Deferme, W.; de Mey, G.; van Langenhove, L. Charge-discharge characteristics of textile energy storage devices having different PEDOT:PSS ratios and conductive yarns configuration. Polymers, 2019, 11, 345. DOI: 10.3390/polym11020345.

[35] Li, E.; Lin, X. Y.; Seet, B.-C.; Joseph, F.; Neville, J. Low profile and low cost textile smart mat for step pressure sensing and position mapping. IEEE Instrumentation and Measurement Technology Conference, 2019, 15641568. DOI: 10.1109/I2MTC.2019.8826892.

[36] Mikkonen, J.; Townsend, R. Frequency-Based Design of Smart Textiles. Proceedings of the $2019 \mathrm{CHI}$ conference on human factors in computing systems ACM, 2019, 294. DOI: 10.1145/3290605.3300524.

[37] Raad, M.; Deriche, M.; Bin Hafeedh, A.; Almasawa, H.; Bin Jofan, K.; Alsakkaf, H.; Bahumran, A.; Salem, M. An IOT based wearable smart glove for remote monitoring of rheumatoid arthritis patients. Biosignals: Proceedings of the $12^{\text {th }}$ International Joint Conference on Biomedical Engineering Systems and Technologies, Vol 4: Biosignals, 2019, 224-228.

[38] D’addio, G.; Evangelista, S.; Donisi, L.; Biancardi, A.; Andreozzi, E.; Pagano, G.; Arpaia, P.; Cesarelli, M. Development of a prototype e-textile sock. IEEE Engineering in Medicine and Biology Society Conference Proceedings, 2019, 1749-1752. DOI: 10.1109/EMBC.2019.8856739.

[39] Di Tore, P. A.; Raiola, G. Powerglove: Genesis of a wearable technology aimed at studying volleyball service. Journal of Human Sport and Exercise, 2019, 14, S77-S83. DOI: 10.14198/jhse.2019.14.Proc1.09. 
[40] Ankhili, A.; Tao, X. Y.; Cochrane, C.; Koncar, V.; Coulon, D.; Tarlet, J.-M. Comparative study on conductive knitted fabric electrodes for long-term electrocardiography monitoring: silver-plated and PEDOT:PSS coated fabrics. Sensors, 2018, 18, 3890. DOI: 10.3390/s18113890.

[41] Bystricky, T.; Moravcova, D.; Kaspar, P.; Soukup, R.; Hamacek, A. A Comparison of embroidered and woven textile electrodes for continuous measurement of ECG. 39th International Spring Seminar on Electronics Technology ISSE, 2016, 7-11. DOI: 10.1109/ISSE.2016.7562871.

[42] Pina, D. S.; Fernandes, A. A.; Jorge, R. N.; Mendes, J. G. Development of a Portable System for Online EMG Monitoring. Proceedings of $20153^{r d}$ Experiment at International Conference (Exp At'15), 2015, 13-16. DOI: 10.1109/EXPAT.2015.7463206.

[43] Caya, M. V. C.; Casaje, J. S.; Catapang, G. B.; Dandan, R. A. V.; Sinsangan, N. B. Warning system for firefighters using e-textile. Proceedings of $20183^{\text {rd }}$ International Conference on Computer and Communication Systems (ICCCS), 2018, 362-366. DOI: 10.1109/CCOMS.2018.8463320.

[44] Litts, B. K.; Kafai, Y. B.; Lui, D.; Walker, J.; Widman, S. Understanding high school students' reading, remixing, and writing codeable circuits for electronic textiles. Proceedings of the 2017 ACM SIGCSE Technical Symposium on Computer Science Education (SIGCSE'17), 2017, 381-386. DOI: 10.1145/3017680.3017740.

[45] Fields, D. A.; Lui, D.; Kafai, Y. B. Teaching computational thinking with electronic textiles: high school teachers' contextualizing strategies in exploring computer science. Proceedings of International Conference on Computational Thinking Education, 2017, 67-72.

[46] Wattuino Nanite 85. Available online: https://shop.watterott.com/Wattuino-Nanite-85-ATtiny85-mit-USBBootloader (accessed on December 5, 2020).

[47] Make: Magazin 4/2015, Maker Media GmbH, Hannover, Germany.

[48] Jutila, M.; Rivas, H.; Karhula, P.; Pantsar-Syväniemi, S. Implementation of a wearable sensor vest for the safety and well-being of children. Proc. Computer Sci., 2014, 32, 888-893. DOI: 10.1016/j.procs.2014.05.507.

[49] Chuang, W.-C.; Hwang, W.-J.; Tai, T.-M.; Huang, D.-R.; Jhang, Y.-J. Continuous finger gesture recognition based on flex sensors. Sensors, 2019, 19 (18), 3986. DOI: 10.3390/s19183986.

[50] Wearable projects. Available online: https://create.arduino.cc/projecthub/projects/tags/wearables?page=1 (accessed on December 5, 2020).

[51] Make Archives - Wearic. Available online: https://www.wearic.com/make/ (accessed online on December 5, 2020).

[52] E-Textiles / Tutorials - learn.sparkfun.com. Available online: https://learn.sparkfun.com/tutorials/tags/etextiles?page=all (accessed online on December 5, 2020).

[53] Instructables circuits: Make your own e-textile Arduino board. Available online: https://www.instructables.com/Make-Your-Own-E-Textile-Arduino-Board/ (accessed online on December 5, 2020).

[54] How to get what you want. Available online: https://www.kobakant.at/DIY/?cat=179 (accessed online on December 5, 2020). 